\title{
College of Occupational Therapists: Position Paper on the Way Ahead for Research, Education and Practice in Mental Health.
}

\author{
Christine Craik MPhil, DMS, Dip COT, MIMgt, SROT \\ Director of Undergraduate Occupational Therapy Studies, Brunel University, \\ Chris Austin DipCOT, BA, SROT \\ Senior Occupational Therapist, Exeter \& District Community Health NHS Trust \\ John D Chacksfield Dip COT, PGCE, SROT \\ Chairman, Association of Occupational Therapists in Mental Health \\ Gabrielle Richards BAppScOT, MScIHWS, SROT Practice Development Tutor \\ Bethlem \& Maudsley NHS Trust \\ Donna Schell DipCOT, SROT \\ Head of Occupational Therapy, St Andrew's Hospital, Northampton
}

Christine Craik MPhil, DMS, Dip COT, MIMgt, SROT

Director of Undergraduate Occupational Therapy Studies, Brunel University, Osterley

Campus, Borough Road, Isleworth, Middlesex,TW7 2DU.

christine.craik@brunel.ac.UK

Chairman of Mental Health Project Working Group of the College of Occupational Therapists 


\begin{abstract}
The future of occupational therapy in mental health has been a topic of reflection and debate. The Education and Research Board (now the Education and Practice Board) of the College of Occupational Therapists created a Working Group to develop a position paper on the way ahead for research, education and practice in mental health. Following consultation, the Working Group reviewed literature, examined current research and surveyed practitioners, managers and educators. From these findings, recommendations have been made which will lead to a firmer evidence base for the practice of occupational therapy in mental health, leading to a more effective use of the expertise of occupational therapists and an improved service for users.
\end{abstract}

\title{
Introduction
}

The College of Occupational Therapists established a Mental Health Project with a remit to develop a position paper to provide a strategy for the College on the way ahead for research, education and practice in mental health. The Project was for one year and with that limitation and the volume of work entailed, it provided an overview of the current situation, an indication of future directions and proposals for further work for the College of Occupational Therapists. While acknowledging that many of the recommendations are addressed to the College, it must be recognised that both individuals and occupational therapy services; members of the Association of Occupational Therapists in Mental Health; together with members and staff of the College will contribute to achieving these recommendation which will lead to an improved service to people with mental health problems. This commitment to 
service users was a prominent feature of the Project and underpins all of the recommendations.

The College of Occupational Therapists must reflect the views and wishes of its members but must also provide a leadership role. Maintaining an effective balance between these is a challenge. In view of the loss of professional management positions, the fragmentation of many services and the relative inexperience of many practitioners, the need for more guidance and leadership has become increasingly evident. Previous advice and statements from the College of Occupational Therapists have been welcomed and appear to have influenced practice. Statements from the College provide guidance not only to occupational therapists but also to the wider audience of people and organisations who influence policy and decision making.

\section{Working Group}

The Working Group was chaired by Christine Craik and the other members were Chris Austin, John Chacksfield, Gabrielle Richards and Donna Schell. Members met a total of 12 times both at formal meetings and in small working groups to deal with various aspects of the work. Reports were presented regularly to the Education and Research Board later the Education and Practice Board.

\section{Process}

The project commenced with a consultation phase when the project was announced and contributions were invited. Thirteen occupational therapists responded; a Workshop was held at the Annual Conference in Southampton with 33 participants 
and a meeting was held with the Occupational Therapy Officer of the Department of Health. Following this, and a review of the College of Occupational Therapists 1997 Research and $\mathrm{PhD}$ register, the following studies were conducted:-

- A review of the literature on occupational therapy in mental health in the UK, USA, Canada and Australia over the past decade. (Craik 1998)

- A survey of 137 occupational therapy practitioners in mental health. (Craik et al 1998)

- A national survey of 120 occupational therapy managers in mental health

- A short qualitative survey of directors of occupational therapy education courses in the UK.

Two of these discrete elements, which form the underpinning of this paper, have already been published in British Journal of Occupational Therapy. It is hoped to publish the remaining two in due course. The position paper is an executive summary synthesising the findings of this work.

\section{Response}

Over 300 occupational therapists responded to the project demonstrating their enthusiasm for, and commitment to, the role of the profession in mental health. They understand that occupation is central to assessment, intervention and outcome in occupational therapy and recognise its influence on the well being of people with mental health problems. Therefore, they wish to remain true to the core principles of occupational therapy and want to understand them better. They identify the need for 
research and an increasing number are equipped to do so. Although committed to working in collaboration with colleagues from other disciplines, they wish to do so in a way which makes the most effective use of their expertise as occupational therapists. They recognise that changes are essential and would welcome guidance.

\section{Research}

The current status of research in occupational therapy in mental health is disappointing but not unexpected given the current lack of funding for major research projects. The literature review revealed a lack of information on the scope, profile and evaluation of practice. Only $27 \%$ of the 120 managers and $15 \%$ of the 137 practitioners surveyed have conducted research not connected to their pre registration education. Thus there is not only a lack of published evidence on which occupational therapists can base their practice but also little on which others may understand the profession. However, there are some encouraging trends. More managers indicated that they facilitated their occupational therapy staff to carry out research; a slightly higher percentage of practitioners educated to degree level rather than diploma level had personally conducted research and the need for more research was identified as a major issue for the profession by educators, practitioners and managers.

\section{Education}


The surveys of educators, practitioners and managers indicated that they had similar views on the issues facing occupational therapy in mental health in the future although they placed different emphasis on them. The survey of practitioners attempted to determine if their pre registration education had been sufficient to meet their needs on first qualifying. Considering the variety of educational establishments attended and the varied length of time since graduating, it is difficult to isolate the effects of pre registration education form previous experience, post qualification supervision and further training. Aspects which were valued during pre registration education were practice as well as theory and good fieldwork placements. Aspects which were not valued were courses which focused more on physical dysfunction and lack of training in specific assessments and techniques. High percentages of managers and practitioners had undertaken additional training and the surveys indicated that occupational therapy specific continuing professional development would be welcomed.

\section{Practice}

The literature review suggested that the clinical subjects featured most often were dementia, work rehabilitation, community mental health and forensic psychiatry, with other subjects either appearing infrequently or not included. While the practitioners study suggested that the majority of occupational therapists did work in community mental health, the emphasis on the other areas was not supported. Diversity of practice was indicated in the literature and supported in the survey with two thirds of practitioners indicating that they were involved with non occupational therapy tasks. While many of these can be attributed to the move towards generic 
working, some seem to be taking occupational therapists beyond the scope of practice.

\section{Recommendations}

While the remit of the project was to provide a strategy for research, education and practice in mental health, it is difficult to separate these aspects and this has only been done where it is considered essential. Indeed, one of our principal recommendations is that there should be closer working between these different aspects of the profession. From the results of the project, short term recommendations are made and emanating from them, recommendations for further work are identified. Together they will lead to a firmer evidence base for the practice of occupational therapy in mental health, leading to a more effective service for users.

In the short term it is recommended that

1. there should be a greater emphasis on the core skills, function and unique approach of occupational therapy in education, research and practice. Building on its existing work, the College of Occupational Therapists should produce statements on these and publicise them widely.

2. occupational therapists should spend the majority of their clinical time working as occupational therapists and not as generalist mental health workers.

3. the College of Occupational Therapists produces a statement clarifying the term evidence based practice and indicates what practitioners can do to make use of 
current evidence. The statement should include references to published examples of good practice

4. the College of Occupational Therapists maintains a database of research in mental health and undertakes a co-ordinating role, initially to ensure that more descriptive studies are conducted to give a fuller picture of current and best practice in occupational therapy in mental health and emanating from these, identifies further research questions.

5. the College of Occupational Therapists, through its own funds, should support and encourage more occupational therapists to undertake research central to validating the practice of occupational therapy in mental health and thus create a group of research occupational therapists able to apply for external funding for larger scale projects.

6. pre registration education should emphasise occupation, specialist occupational therapy knowledge and skills, and the ability to work in a multidisciplinary context not a generic one. High quality fieldwork experience in mental health is important and where possible should be in services which have a specific occupational therapy focus.

7. post registration education should emphasise deepening knowledge of occupation and occupational therapy, through continuing professional development, formal qualifications and research activity. 
8. the College of Occupational Therapists strengthens current links with other organisations in mental health and forges new links with other organisations especially those representing users and undertakes collaborative work where appropriate.

9. the specialist role and function of occupational therapy in mental health should be promoted both within the College and to other organisations by activities such as major conferences, Occupational Therapy Day and the Annual Conference.

10.the College of Occupational Therapists, in conjunction with the Association of Occupational Therapists in Mental Health, should prepare timely guidance to members on government policy and major reports from other organisations.

11.the College of Occupational Therapists uses its membership database to identify, on an annual basis, the number of therapists working in mental health, monitor trends and take remedial action should the number fall.

In the long term it is recommended that

12.based on the core skills, role and unique approach of occupational therapy in mental health, studies should be conducted to identify effective assessments, models of practice, interventions and outcome measures. This information should then guide education, practice and further research. 
13.studies should be conducted to enable the College of Occupational Therapists to give more precise guidelines about the percentage of clinical time occupational therapists should spend working as occupational therapists rather than generalist mental health workers. It should identify the tasks this includes especially those tasks which are considered outside the scope of practice.

14.the College of Occupational Therapists should continue to promote the creation and use of evidence based practice

15.the College of Occupational Therapists develops a central focus for in research in occupational therapy in mental health by co-ordinating small scale multi site studies; by working towards establishing a common methodology to enhance the validity and reliability of such studies; by developing previous studies and by commissioning key pieces of research.

16.the College of Occupational Therapists should assist research active occupational therapists in mental health to obtain external research funding

17.the College of Occupational Therapists in collaboration with other organisations in mental health, especially those representing service users, should commission joint research

18.the College of Occupational Therapists continues to promote the specialist role of occupational therapy in mental health and encourages dissemination of studies both in British Journal of Occupational Therapy and other publications. 


\section{Conclusion}

This position paper is based on the views of many occupational therapy practitioners, educators and managers in the UK and suggests a way ahead for research, education and practice in mental health. It is hoped that it will be discussed and debated widely both within the profession and beyond. The implementation of its recommendations should lead to a better service for users and more effective use of occupational therapists in the health and social care settings of the future. 


\section{References}

Craik C (1998) Occupational therapy in mental health: a review of the literature, British Journal of Occupational Therapy, 61(5), 186-92

Craik C, Chacksfield J D, Richards G (1998) A survey of occupational therapy practitioners in mental health, British Journal of Occupational Therapy, 61(5), 227234 